\title{
SIMPLE METHODS OF EXAMINATION IN PARAPLEGIA: II. THE COUGH RESPONSE OF THE EXTERNAL ANAL SPHINCTER
}

\author{
By ERnest Bors, M.D. \\ Spinal Cord Injury Service of the Veterans Administration Hospital, Long Beach, California, \\ and the Department of Surgery, University of California School of Medicine, Los Angeles, \\ California
}

\section{INTRODUCTION}

RECTAL examination of the external anal sphincter contributes information regarding the function of the sacral cord segments. This examination permits assessment of the external anal sphincter with regard to its tone, its response to testing the bulbocavernosus reflex (Bors, 1945), its volitional contraction and relaxation, and its response to coughing. While the external anal sphincter tone and bulbocavernosus reflex have been studied in paraplegic and in non-paraplegic individuals (Bors \& Blinn, 1957, 1959; Pierce, Roberge \& Newmann, 1960) and while the significance of volitional movements of this muscle is self-explanatory, its response to coughing has not yet been described as a diagnostic tool. The following report attempts to show that the cough response of the external anal sphincter permits certain deductions in regard to the motor function of the abdominal muscles.

\section{MATERIAL AND METHOD}

Seventy male patients with traumatic cord lesions were examined. Forty patients had thoracic or lumbar and 30 patients had cervical cord injuries. Thirty of the 40 patients in the thoracolumbar group and 12 of the 30 patients in the cervical group had clinically complete lesions. The age of the patients in the thoracolumbar group ranged from 20 to 72 years, and the time interval between injury and examination ranged from minimum of 3 weeks to a maximum of 242 months (20 years and 2 months). The age of the patients in the cervical group ranged from $2 \mathrm{I}$ to 65 years and the interval between injury and examination was I to 192 months (I6 years).

The rectal examination was performed with the patient in a supine (face up) position. This position was used for all patients, including those who were able to stand or walk, and thus differed from the usual method of rectal examination done in urology for exploring the prostate. The supine position eliminates associated movements of the pelvic floor musculature which may be caused by weightbearing. The external anal sphincter tone was assessed by the resistance it posed to the digit. Next, the patient was asked to contract and to relax his external anal sphincter. The bulbocavernosus reflex was then tested by gently squeezing the glans penis (or by an additional tug on the catheter whether suprapubic or intra-urethral). Finally, the patient was asked to cough and the response of the sphincter noted A positive (normal) response consisted of a brisk, unsustained contraction of the external anal sphincter.

The rectal examination was, of course, preceded by a neurological examination which included testing the abdominal muscles by searching for Beevor's sign. This well-known sign indicates by the direction of the shift of the umbilicus which 
part of the abdominal musculature, if any, is still under volitional control. Beevor's sign was elicited in the common fashion by asking the supine patient to lift his head against the resistance exerted by the examiner's hand.

\section{OBSERVATIONS}

I. Forty patients had thoracic or lumbar lesions (Table I)

I. Of 30 patients who had clinically complete lesions, I9 had positive cough responses of the external anal sphincter, Io had negative responses, and one had an equivocal response.

\section{TABLE I}

Cough Response of the External Anal Sphincter in 30 Patients with Clinically Complete Thoracic or Lumbar Cord Lesions

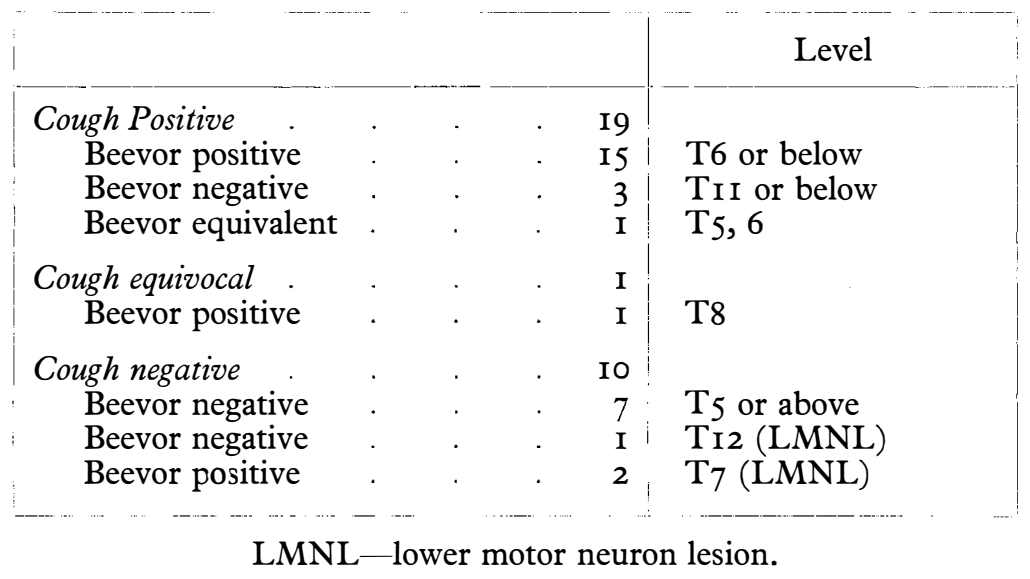

All patients with positive responses had levels at or below T6. Fifteen of these had positive Beevor's signs. This sign was absent in three patients whose segmental level was at or below Tir. The one patient with an equivocal cough response had a positive Beevor's sign; his level was at T8.

Of the Io patients with negative cough responses, two must be omitted because their external anal sphincters were flaccid owing to lower motor neuron lesions; one had a lesion at $\mathrm{T}_{7}$, the other at $\mathrm{T}_{12}$. Of the remaining eight patients, all but one had segmental levels above $\mathrm{T}_{5}$; the exceptional patient had a level at $\mathrm{T}_{7}$. Beevor's sign was absent in all eight patients, seven of whom had segmental levels above $\mathrm{T}_{5}$ and one had a TI 2 lesion. Per contra, a positive Beevor's sign was present in two patients, both mentioned above, with lesions at $\mathrm{T}_{7}$, one with a lower motor neuron lesion below that level and the other with the exceptional absence of the cough response.

2. Ten patients had clinically incomplete lesions. Five of these had positive, and the other five had negative cough responses of the external anal sphincter (Table II).

All those with positive cough responses had lesions at or below T6, including one whose T8 lesion was so incomplete as to permit walking and volitional contraction and relaxation of the external anal sphincter. He was the only one with a 
TABLE II

Cough Response of the External Anal Sphincter in Io Patients with Clinically Incomplete Thoracic or Lumbar Cord Lesions

\begin{tabular}{|c|c|c|c|}
\hline & & & Level \\
\hline $\begin{array}{l}\text { Cough positive } \\
\text { Beevor positive (Vol. sph.) } \\
\text { Beevor negative }\end{array}$ & $\begin{array}{l}\cdot \\
\cdot \\
\cdot\end{array}$ & $\begin{array}{l}5 \\
I \\
4\end{array}$ & $\begin{array}{l}\mathrm{T} 8 \\
\mathrm{~T} 6, \mathrm{~L}_{2}(3)\end{array}$ \\
\hline $\begin{array}{l}\text { Cough negative } \\
\text { Beevor positive } \\
\text { Beevor negative }\end{array}$ & . & $\begin{array}{l}5 \\
0 \\
5\end{array}$ & $\begin{array}{l}\text { O } \\
\text { TI, T4(2) } \\
\text { TI2 (LMNL) } \\
\text { L3 (LMNL) }\end{array}$ \\
\hline
\end{tabular}

Vol. sph. $=$ volitional sphincter movement.

$\mathrm{LMNL}=$ lower motor neuron lesion.

Beevor's sign in this group; the remaining four patients had none; the respective segmental levels of the latter were T6, L2, L2 and L2.

Of the five patients with negative cough responses, two must be omitted because their external anal sphincters were flaccid due to lower motor neuron lesions at $\mathrm{T}_{12}$ and $\mathrm{L}_{3}$, respectively; they had, of course, no Beevor's sign. None of the remaining three patients with negative cough responses had Beevor's sign because of their respective levels at $\mathrm{T}_{1}, \mathrm{~T}_{5}$ and $\mathrm{T}_{5}$. None had volitional movements of the external anal sphincter.

\section{Thirty patients had cervical cord lesions}

I. Twelve patients had clinically complete cervical cord lesions (Table III). None of these had a positive cough response or volitional movement of the external

TABLE III

Cough Response of the External Anal Sphincter in I2 Patients with Clinically Complete Cervical Lesions

\begin{tabular}{|c|c|c|}
\hline Cough negative I2 & Motor levels & Sensory levels \\
\hline & $\mathrm{C}_{4}$ to $\mathrm{C} 8$ & $\mathrm{C}_{5}$ to T2 \\
\hline
\end{tabular}

enal sphincter, although all had a good rectal sphincter tone and a prompt bulbocavernosus reflex. None, of course, had a Beevor's sign. The highest motor deficit was at $\mathrm{C}_{4}$, the lowest at $\mathrm{C}_{3}$; the highest sensory deficit was at $\mathrm{C}_{5}$, the lowest at $\mathrm{T}_{2}$.

2. Eighteen patients had clinically incomplete cervical cord lesions (Table IV). Thirteen had a positive and one an equivocal cough response; seven had volitional movement of the external anal sphincter. All patients had good sphincter tone and a prompt response to testing the bulbocavernosus reflex. Only two had a positive Beevor's sign; 17 had sensory sacral sparing. 


\section{TABLE IV}

Cough Response of the External Anal Sphincter in I8 Patients with Clinically Incomplete Cervical Lesions

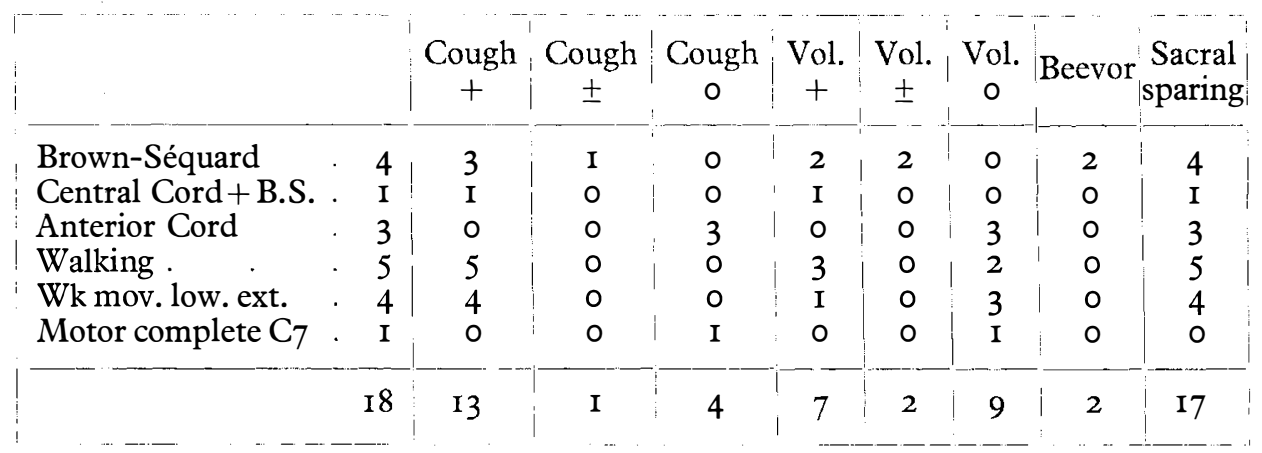

B.S. $=$ Brown-Séquard.

Vol. = Volitional sphincter movement.

Wk mov. low. ext. $=$ Weak movement of lower extremities.

When a diagnostic analysis of the patients was attempted, it showed that the majority of patients with positive cough responses had lesions which would not interfere with the innervation of the abdominal musculature. This group comprised four patients with Brown-Séquard lesions (including one with an equivocal cough response), one with a predominantly central cord syndrome of Schneider (I954), five who were able to walk with the aid of Canadian crutches or a cane (some with partial bracing of one lower extremity), and four who had at least some weak active movement in thelower extremities. Of four patients with a negative cough response, three had a typical anterior cord syndrome of Schneider (1955), and the fourth patient had a motor deficit below $\mathrm{C}_{7}$ and had only an incomplete lesion with regard to his sensory deficit which started below TII.

Beevor's sign was positive only in two patients with Brown-Séquard lesions; the deviation of the umbilicus pointed, as expected, to the side with retained motor function.

Volitional movement of the external anal sphincter was retained in two patients with Brown-Séquard lesions and was equivocal in two others. It was retained in the one patient with the central cord syndrome, in three of the walking patients and in one patient with weak movements of the lower extremities.

Sacral sensory sparing was present in 17 of the 18 patients, being absent only in one. Analgesia usually correlated with the loss of volitional movement of the external anal sphincter.

\section{DISCUSSION}

The digital examination of external anal sphincter responses in general and the cough response in particular is admittedly a rough method if compared either with manometric (Schuster, Hookman, Hendrix \& Mendeloff, I965; Dubin \& Morales, I965) or with electromyographic techniques (Bors \& Blinn, I957, I959; Taverner \& Smiddy, I959; Pierce, Roberge \& Newmann, I960; Scott, Queseda 
\& Cardus, I964). However, it is simpler than the other methods, which should be applied in doubtful responses; e.g. I routinely use electromyography of the external anal sphincter when the bulbocavernosus reflex is equivocal on digital examination.

Relaxation of the patient in the supine position with outstretched legs is essential, once the finger has been introduced into the rectum. Postural changes influence the anal sphincter tone, although this may be a transient process in the subject with a normal neuraxis (Taverner \& Smiddy, 1959).

In the majority of patients with complete and incomplete lesions of the thoracolumbar cord the following findings obtained: If the cough response and Beevor's sign were negative, the lesion was at or above $\mathrm{T}_{5}$; if the cough response was positive but Beevor's sign was negative, the level was below TII; if the cough response and Beevor's sign were positive, the lesion was between T6 and TII. Obviously both signs correlated with the abdominal myotomes in the overwhelming majority of patients. There were only two exceptions, and one of the two patients had a lower motor neuron lesion below $\mathrm{T}_{7}$ in regard to the pelvic floor musculature, as evidenced by a flaccid external anal sphincter.

The observation made in patients with thoracolumbar cord lesions applied also to those with cervical lesions; namely, the cough response of the external anal sphincter reflected the state of innervation of the abdominal musculature. Therefore, this response was absent in all patients with clinically complete cervical cord lesions and in those patients with an anterior cord syndrome. Volitional movement and the cough response of the external anal sphincter were not necessarily correlated; the cough response was present in spite of the absence of volitional movement, but not the reverse; present volitional movement predicted a positive cough response in the traumatic para- or tetraplegic patient. Volitional movement correlated with the modality of sacral sparing, i.e. it was usually absent with analgesia.

As was to be expected, the absence of Beevor's sign in complete cervical cord lesions and anterior cord syndromes indicated the loss of volitional control in any of the abdominal myotomes. Thus patients without a Beevor's sign, without a cough response and without volitional movement of the external anal sphincter had a motor lesion above T6, in spite of sensory sparing in sacral or other dermatomes of modalities not conducted in the lateral columns.

In brief, these observations tend to confirm the belief that the cough response is a purely spinal reflex and a protective mechanism elicited by an increase in the intra-abdominal pressure. It has been shown manometrically in persons with an intact neuraxis, in whom coughing produced an increased intrarectal pressure associated with relaxation of the internal anal sphincter, that the contraction of the external anal sphincter was the sole source of fecal continence (Schuster et al., I965).

Furthermore, the observations indicated that the diaphragm alone would not raise the intra-abdominal pressure sufficiently to induce a cough response of the external anal sphincter; for that, at least one abdominal myotome had to remain volitionally innervated.

An increase of sphincter tone during inspiration has been demonstrated electromyographically by Taverner and Smiddy (1959) in normal subjects. A similar observation was made in one of our patients with a Brown-Séquard syndrome whose anal sphincter responded more on deep inspiration than on coughing.

The digital examination of the cough response of the external anal sphincter does not pretend to compete with manometric or electromyographic tests. The 
latter are indicated, as mentioned before, when information obtained by this simple clinical test is equivocal. However, as a quick method of orientation the digital test, in conjunction with an evaluation of Beevor's sign, allows an appraisal of the motor deficit of the abdominal musculature.

\section{SUMMARY}

The characteristics of the external anal sphincter were noted in 40 paraplegic and 30 tetraplegic patients.

It was found that contraction of the sphincter in response to coughing is a spinal reflex and is present as long as the motor deficit of the abdominal musculature leaves at least one myotome under volitional control.

The cough response of the external anal sphincter per se, and especially, in combination with an evaluation of Beevor's sign, was found to be a practical clinical diagnostic tool.

The findings are discussed and pertinent literature is quoted.

\section{RÉSUMÉ}

Les caractéristiques du sphincter externe ont été notées chez 40 paraplégiques et 30 tétraplégiques. Il a été trouvé que la contraction du sphincter qui suit la toux est un réflexe spinal et a été trouvé présent pour autant qu'il subsiste, au niveau de l'abdomen, au moins un myotome sous contrôle volontaire. La réponse à la toux du sphincter anal externe, per se, et spécialement associée à l'évaluation du signe de BEEVOR, a été utilisée sur le plan clinique pratique comme méthode de diagnostic. Les résultats ont été discutés et mention faite de la littérature qui s'y rapporte.

\section{ZUSAMMENFASSUNG}

Das Verhalten des Sphincter ani externus wurde an 40 paraplegischen und 30 tetraplegischen Patienten untersucht. Die Kontraktion des Sphincter nach Husten erwies sich als ein spinaler Reflex, der auftrat, solange zum mindesten ein Myotom der Bauchmuskeln willkürlich innerviert blieb. Die Reaktion des externen Sphincter ani auf Husten, zusammen mit der Auswertung von 'Beevors sign', erwies sich als ein praktisches diagnostisches Hilfsmittel. Die Ergebnisse werden diskutiert und die einschlägige Literatur angegeben.

\section{ACKNOWLEDGMENT}

I wish to express my appreciation to R. W. Porter, M.D., Chief of Neurosurgery, V.A. Hospital, Long Beach, California, for reading the manuscript and making valuable suggestions, and to Mrs. Olive Snow of the Spinal Cord Injury Service, V.A. Hospital, Long Beach, California for preparing the manuscript.

\section{REFERENCES}

Bors, E. (1945). Transverse Myelitis Conference, 9th Service Command, Army Service Forces, War Department.

Bors, E. \& Blinn, K. A. (1957). Arch. Neurol. Psychiat. 78, 339.

Bors, E. \& Blinn, K. A. (1959). F. Urol. 82, I28.

Dubin, L. \& Morales, P. (I965). F. Urol. 93, 57.

Pierce, J. M., Jr., Roberge, J. T. \& Newmann, M. M. (1960). F. Urol. 83, 319.

SCHNEIDER, R. C. (1955). F. Neurosurg. I2, 95.

SChneider, R. C., Cherry, G. \& PANTeK, H. (1954). F. Neurosurg. II, 546.

Schuster, M. M., Hookman, P., Hendrix, T. R. \& Mendeloff, A. I. (1965). Bull. fohns Hopkins Hosp. I16, 79.

ScotT, F. B., QueSEda, E. M. \& Cardus, D. (1964). F. Urol. 92, 455.

Taverner, D. \& Smiddy, F. G. (1959). Dis. Colon Rect. 2, I53. 